\title{
Endothelial Dysfunction in Lacunar Stroke: A Systematic Review
}

\author{
Iris L.H. Knottnerus ${ }^{a}$ Hugo Ten Cate ${ }^{b, c}$ Jan Lodder ${ }^{a, b}$ Fons Kessels ${ }^{d}$ \\ Robert J. van Oostenbrugge $\mathrm{e}^{\mathrm{a}, \mathrm{b}}$ \\ ${ }^{a}$ Department of Neurology, ${ }^{b}$ Cardiovascular Research Institute Maastricht (CARIM), ' Laboratory for Clinical \\ Thrombosis and Haemostasis, Department of Internal Medicine, and d Department of Clinical Epidemiology and \\ Medical Technology Assessment (KEMTA), Maastricht University Medical Centre, Maastricht, The Netherlands
}

\section{Key Words}

Endothelium $\cdot$ Vessel wall $\cdot$ Lacunar stroke $\cdot$ Endothelial

dysfunction $\cdot$ Cerebral small-vessel disease

\begin{abstract}
Background: Endothelial dysfunction is thought to play an important role in the pathogenesis and progression of cerebral small-vessel disease in lacunar stroke patients. Methods: We systematically searched the literature (MEDLINE, EMBASE) for evidence of endothelial activation and dysfunction in lacunar stroke. The selected papers were assessed by a predefined checklist to estimate methodological and informative quality. The papers were categorized into subheadings concerning the different physiologic functions of the endothelium and a subheading concerning toxins for the endothelium. Results: 29 articles were eligible for further analysis. We found 16 publications on regulation of vascular tone by the endothelium, which showed an impaired function at several time points after the stroke by means of different clinical methods (e.g. flow-mediated vasodilatation and $\mathrm{CO}_{2}$ reactivity). Nine references showed elevated levels of markers of hemostatic function of the vascular endothelium (e.g. von Willebrand factor, thrombomodulin) in acute and subsequent phases. In 4 papers, adhesion molecules (e.g. E- and P-selectin) were elevated only during the acute phase. Homocysteine, a toxin for the endothelium, was elevated in patients in 3 papers. Conclusions: The cur-
\end{abstract}

rent literature suggests that endothelial dysfunction might be involved in the pathogenesis of lacunar stroke, especially in those patients with concomitant silent lacunar infarcts and ischemic white matter lesions. Future research on endothelial function in lacunar stroke should concentrate on long-term clinical as well as radiological follow-up in welldefined cases and combine multiple methods to evaluate endothelial function.

Copyright $\odot 2009$ S. Karger AG, Basel

\section{Introduction}

Lacunar infarction accounts for a quarter of all ischemic strokes [1]. By definition, lacunar infarcts are small infarcts (2-20 $\mathrm{mm}$ in diameter) located in the basal ganglia, the deep cerebral white matter or the brainstem and are the result of occlusion of a single small perforating cerebral artery [2]. Fisher observed that this occlusion could be caused either by a general destructive process of the microvessels termed segmental arterial disorganization (arteriolosclerosis or lipohyalinosis) or by a local atherosclerotic process termed microatheromatosis [3].

The endothelium has a variety of physiological functions, such as the expression of adhesion molecules, maintenance of adequate vessel tone and hemostasis. Endothelial cell activation is - among others - characterized

\section{KARGER}

Fax +4161306 1234 E-Mail karger@karger.ch www.karger.com
(ㄷ) 2009 S. Karger AG, Basel

$1015-9770 / 09 / 0275-0519 \$ 26.00 / 0$

Accessible online at:

www.karger.com/ced
I.L.H. Knottnerus

Department of Neurology

Maastricht University Medical Centre, PO Box 5800

NL-6202 AZ Maastricht (The Netherlands)

Tel. +31 43387 5062, Fax +31 43387 7055, E-Mail iris.knottnerus@neurologie.azm.nl 
by the increased or de novo expression of leukocyte adhesion molecules [E-selectin, P-selectin, intracellular adhesion molecule-1 (ICAM-1) and vascular cell adhesion molecule-1 (VCAM-1)] and a change in phenotype from anticoagulant to procoagulant [e.g. loss of surface thrombomodulin (TM)] $[4,5]$.

Recent observations suggest that activation of the cerebral microvascular endothelium might be the primary step in the pathogenesis of lacunar stroke, subsequently leading to increased permeability of the blood-brain barrier (BBB). This increased permeability allows blood products to reach the perivascular space and cause glial and neuronal damage [6-8].

For this review, we systematically searched the literature for evidence of endothelial activation and dysfunction in symptomatic lacunar stroke.

\section{Methods}

\section{Search Strategy}

We searched the published literature from January 1966 (MEDLINE) and from January 1989 (EMBASE). By way of the advanced search method, we combined the following terms: 'small vessel disease', 'small artery disease', 'micro-angiopathy', 'lacunar stroke', 'lacunar infarction', 'lacunar syndrome', 'lipohyalinosis' and 'micro-atheromatosis' using the Boolean operator 'OR'. We used the Boolean operator 'AND' to link these to the terms 'endothelium', 'vessel wall', 'endothelial dysfunction', 'endothelial cell activation', 'endothelial activation', 'cerebrovascular reactivity' and 'blood-brain barrier'. The search was updated until August 2008.

\section{Eligibility of Studies}

We sought publications with original data on humans suffering from lacunar stroke. Articles without stroke classification or articles concerning only large-vessel stroke, cardioembolic stroke or hemorrhagic stroke were excluded. Only articles in English, Dutch and German were included, as the authors were familiar with these languages. We excluded studies relating to genetically determined cerebral small-vessel disease, such as cerebral autosomal dominant arteriopathy with subcortical infarcts and leukoencephalopathy. The references in the selected articles were scanned for other relevant articles, using the same criteria.

Two authors (I.K. and R.O.) independently selected articles in the above-stated manner. A third reviewer (J.L.) resolved any discrepancies.

Since the endothelium possesses different physiologic functions - i.e. regulation of vessel tone, hemostasis, expression of adhesion molecules - we categorized the studies into subheadings. Our search strategy also generated articles on toxins for the endothelium; those were categorized separately.

The methodological and informative qualities of the selected studies were assessed independently by 2 authors (I.K. and R.O.) by means of a predesigned checklist (supplementary material, please see www.karger.com/doi/10.1159/000212672).

\section{Results}

By searching MEDLINE and EMBASE we found 111 papers. Applying the above-mentioned criteria yielded a total of 17 articles that were suitable for further analysis [9-25]. The main reasons for excluding papers were noncerebral disease $(\mathrm{n}=31)$, silent cerebral small-vessel disease $(n=18)$, reviews $(n=19)$ and language $(n=12)$. Scanning the references of the selected articles added another 12 articles [15, 26-36]. The main characteristics of the studies and their quality assessed by the checklist are provided in table 1. Background information and main findings of the studies for each subheading are discussed below.

\section{Regulation of Vascular Tone}

One of the most important vasoactive substances released by the endothelium is nitric oxide (NO). NO is synthesized by endothelial constitutive NO synthase, using the L-arginine as substrate. NO stimulates guanylyl cyclase in the vascular smooth muscle cells, which leads to vasodilatation and increased blood flow. Various pharmacological (e.g. bradykinin) and physical (e.g. shear stress) stimuli lead to the release of NO [4]. In addition to vasodilatory substances, the cerebral endothelium secretes vasoconstrictive substances, known as endothelins (ETs). The balance between these substances is thought to regulate the basal tone of the blood vessels.

Shear stress, induced by a rise in blood flow due to a short ischemic episode in distal tissue, induces vasodilatation through the release of NO by the endothelium (flow-mediated vasodilatation, FMD). FMD can be assessed by ultrasonography by measuring the change in diameter in response to increased blood flow in the brachial artery [4]. Two studies assessed FMD in lacunar stroke patients, whereas only 1 study assessed endothelium-mediated vasodilatation after infusion of L-arginine (an NO donor) by measuring the change in mean arterial velocity in the middle cerebral artery $[9,17,27]$. These studies showed an impaired response in FMD and L-arginine reactivity, which improved in both patients with lacunar stroke and patients with a similar risk factor profile after treatment with atorvastatine [17].

$\mathrm{NO}$ is important for the modulation of $\mathrm{CO}_{2}$-mediated cerebral blood flow in healthy humans [37], and an impaired $\mathrm{CO}_{2}$ vasoreactivity was found in patients with endothelial dysfunction [38]. We found 4 studies on $\mathrm{CO}_{2}$ vascular reactivity in symptomatic lacunar stroke patients $[23-26,36,39]$. All studies found impaired vasomotor reactivity at different time intervals after the isch- 
emic event. Similar results were found by 2 studies which used acetazolamide $[25,39]$.

Six studies $[10,15,19,29,32,33]$ focused on functional gene polymorphisms known to be involved in the regulation of NO and ET activity. None of the polymorphisms of ET seem relevant to lacunar stroke [10], but two polymorphisms of the endothelial constitutive NO synthase gene - intron 4ab [19] and Glu298Asp [29] - are associated with the occurrence of lacunar stroke. From most studies, the direct mechanism by which the polymorphism influences the pathogenesis of lacunar stroke can only be hypothesized from the function of NO, because the end products (NOx and ET) were not determined due to the abluminal localization of ET and the oxidation of NO.

Asymmetric dimethylarginine (ADMA) is an endogenous inhibitor of NO, and it may play a role in mediating endothelial dysfunction [40]. In lacunar stroke patients, the grade of leukoaraiosis was positively correlated with the levels of ADMA, compared to community controls free of cerebrovascular disease [18].

\section{Hemostatic Function of the Endothelium}

Vascular endothelial function can be studied by measuring the levels of molecules of endothelial origin [4].

TM is produced and expressed on the endothelial cell surface, where it mediates the activation of protein $\mathrm{C}$ upon binding to thrombin. Activated protein $C$ inhibits, by proteolytic cleavage, the cofactors Va and VIIIa of the coagulation cascade. Release of the soluble form of TM (sTM) is regarded as a marker of endothelial cell activation [41]. We found 5 studies which measured sTM levels in lacunar stroke patients $[13,14,16,20,31]$. Studies which evaluated patients during the chronic phase found higher levels of sTM in patients than in controls, especially in those with multiple lacunar infarcts and leukoaraiosis [13].

Von Willebrand factor (vWF) is mainly found in endothelial cells (Weibel-Palade bodies), but to some extent also in blood platelets ( $\alpha$-granules). vWF connects the activated blood platelet to the subendothelial collagen. In plasma, it circulates in a noncovalent complex with coagulation factor VIII [42]. Several different assays are used to determine either the concentration or the function of vWF. We found 6 studies on vWF in lacunar stroke patients, 4 of which measured concentrations of vWF [16, $28,34,35]$, whereas 2 determined its activity [14,31]. Most studies show elevated levels and activity of vWF within days of ictus and also after several months.

Endothelial Dysfunction in Lacunar Stroke
Tissue factor (TF) is a protein which is located at extravascular sites not exposed to the blood, i.e. adventitial fibroblasts and vascular smooth muscle cells. TF is encountered by the blood in case of injury or endothelial disruption. The contact between TF and factor VII(a) leads to the formation of an active complex which activates factor $\mathrm{X}$ and factor IX. The physiological inhibitor of TF is the tissue factor pathway inhibitor (TFPI), which binds to activated factor Xa within the TF-VIIa-Xa complex, thus limiting thrombin formation. TFPI is mainly present in endothelial cells [43]. We found only 1 study on TF and TFPI in lacunar stroke patients, which showed an association between levels of soluble TF and the extent of leukoaraiosis, but no association with the number of lacunes. Elevated levels of TFPI were found in patients with isolated lacunar infarction compared to either patients with leukoaraiosis or healthy controls [13].

Endothelial cells synthesize and release tissue plasminogen activator (tPA) into the bloodstream. tPA mediates the conversion of plasminogen to plasmin, which breaks down fibrin. The possession of a thymidine $(\mathrm{T})$ allele $(-7351 \mathrm{C} / \mathrm{T}$ polymorphism) is associated with reduced DNA transcription approximately leading to half the tPA release observed in those homozygous for the cytosine (C) allele [44]. Jannes et al. [12] found a significant association between the TT genotype of the $\mathrm{TPA}-7351 \mathrm{C} /$ $\mathrm{T}$ polymorphism and lacunar stroke. Unfortunately, levels of tPA were not assessed in this population, so the influence of the polymorphism on levels of tPA could not be evaluated.

\section{Serum Markers of Vascular Inflammation}

Selectins are transmembrane glycoproteins expressed on activated vascular endothelium (E- and P-selectin) and activated platelets (P-selectin). These adhesion molecules attract leukocytes from the circulation and promote leukocyte rolling along the endothelium. The leukocytes adhere to the endothelium through the actions of ICAM-1 and VCAM-1 [45]. Besides being expressed by the endothelium, ICAM-1 is also expressed by leukocytes [46]. Soluble isoforms of the adhesion molecules are present in the circulation after cellular activation [47]. We found 4 studies reporting on the serum levels of adhesion molecules in lacunar stroke patients [13, 14, 28, 35]. Elevated levels of $\mathrm{E}$ - and $\mathrm{P}$-selectin were confined to the acute phase in most studies. The authors explained the fall in levels of P- and E-selectin after 3-6 months by the widespread use of cholesterol-lowering agents and antithrombotic therapies [28]. ICAM-1 levels were elevated in both isolated lacunar infarction and ischemic leukoara-

Cerebrovasc Dis 2009;27:519-526 
Table 1. Selected papers on endothelial dysfunction in symptomatic lacunar stroke

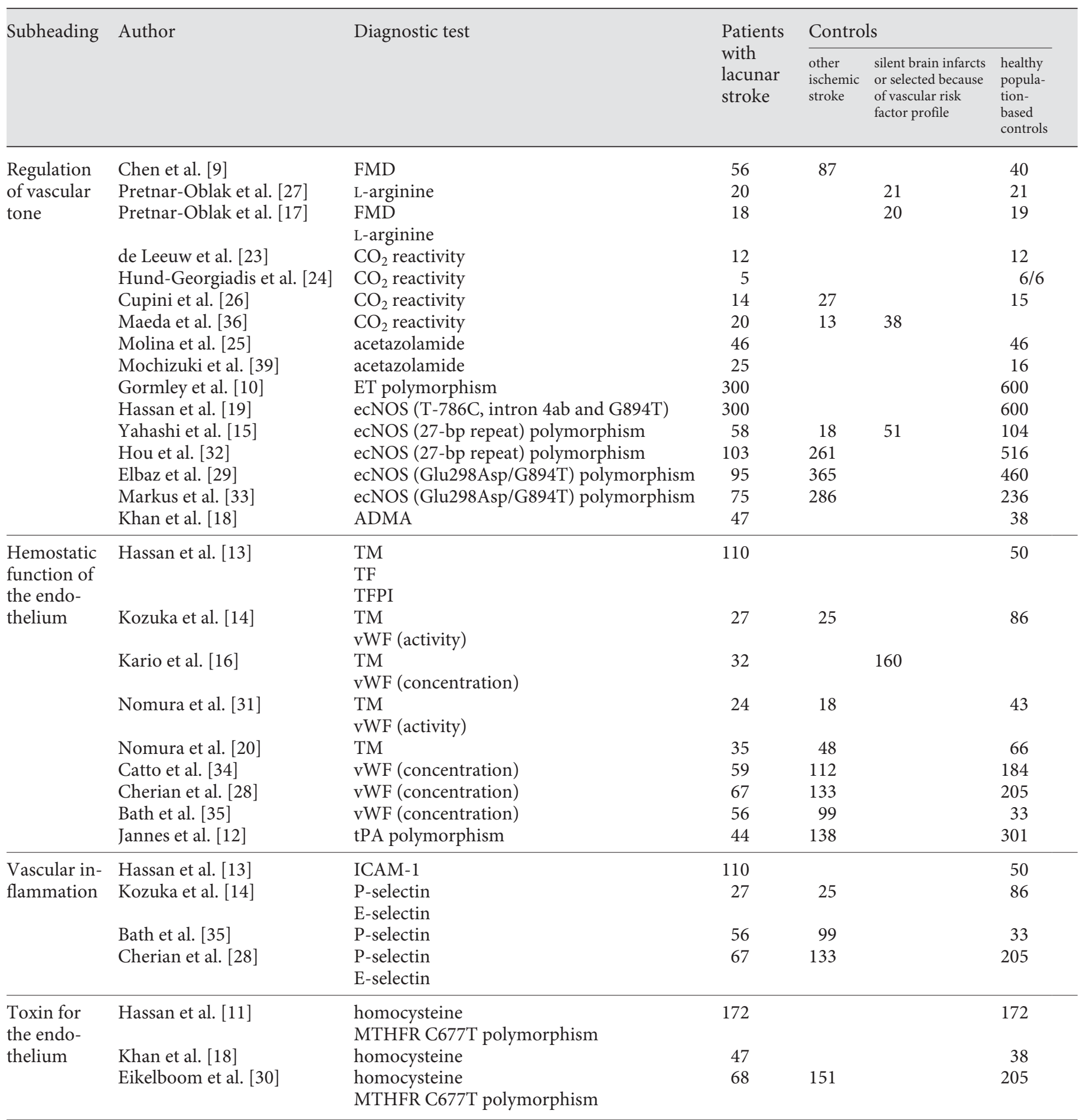

$\uparrow / \downarrow$ : Elevated or reduced levels of endothelial marker (or functional test) in patients with lacunar stroke compared to (healthy) controls; =: no differences in levels between patients and controls; -: not tested. FMD = Flow-mediated vasodilatation; ecNOS = endothelial constitutive nitric oxide synthase; ET = endothelin; $\mathrm{ADMA}=$ asymmetric dimethylarginine; $\mathrm{TM}=$ trombomodulin;
$\mathrm{TF}=$ tissue factor; $\mathrm{TFPI}=$ tissue factor pathway inhibitor; $\mathrm{vWF}=$ von Willebrand factor; tPA = tissue plasminogen activator; ICAM-1 = intracellular adhesion molecule-1; MTHFR = methylene tetrahydrofolate reductase; LI/LA = isolated lacunar infarct/ischemic leukoaraiosis, as proposed by Hassan et al. [13]. 


\begin{tabular}{|c|c|c|c|c|c|}
\hline \multirow{2}{*}{$\begin{array}{l}\text { Age of patients } \\
\text { (controls), years }\end{array}$} & \multirow{2}{*}{$\begin{array}{l}\text { Quality of article } \\
\text { (checklist) }\end{array}$} & \multirow{2}{*}{$\begin{array}{l}\text { Classification of } \\
\text { stroke subtype }\end{array}$} & \multicolumn{3}{|c|}{ Conclusions } \\
\hline & & & acute (days) & $\begin{array}{l}\text { subacute } \\
\text { (1 month) }\end{array}$ & $\begin{array}{l}\text { chronic } \\
\text { ( } \geq 3 \text { months })\end{array}$ \\
\hline $68(68 / 67)$ & $18 / 28$ & TOAST [49] & $\downarrow$ & - & - \\
\hline $61(61 / 60)$ & $15 / 28$ & TOAST & - & $\downarrow$ & - \\
\hline \multirow[t]{2}{*}{$61(63 / 59)$} & $18 / 28$ & TOAST & - & $\downarrow$ & $=$ \\
\hline & & & - & $\downarrow$ & $=$ \\
\hline $58(52)$ & $17 / 28$ & TOAST & $\downarrow$ & - & - \\
\hline $62(25 / 57)$ & $16 / 28$ & not given & - & - & $\downarrow$ \\
\hline $61(58 / 58)$ & $19 / 28$ & image-based & - & $\downarrow$ (1-3 months $)$ & - \\
\hline $60(57 / 58)$ & $13 / 28$ & NINDS [51] & - & $\downarrow$ & - \\
\hline $57(58)$ & $19 / 28$ & clinic- and image-based & - & $\downarrow$ & - \\
\hline $62(58)$ & $13 / 28$ & clinic- and image-based & $\downarrow$ & - & - \\
\hline $67(67)$ & $17 / 26$ & $\mathrm{LI} / \mathrm{LA}$ & $=$ & & \\
\hline $67(67)$ & $17 / 26$ & LI/LA & \multicolumn{3}{|c|}{ intron-4ab insertion-deletion genotype associated with LI } \\
\hline $70(70 / 68)$ & $14 / 26$ & NINDS & \multicolumn{3}{|c|}{$=$} \\
\hline $67(67 / 66)$ & $11 / 26$ & NINDS & \multicolumn{3}{|c|}{$=$} \\
\hline $70(69 / 68)$ & $16 / 26$ & clinic- and image-based & \multirow{2}{*}{\multicolumn{3}{|c|}{ homozygosity for $\mathrm{G}$ allele in lacunar stroke }} \\
\hline $66(66 / 65)$ & $13 / 26$ & clinic- and image-based & $=$ & & \\
\hline $65(67)$ & $16 / 28$ & $\mathrm{LI} / \mathrm{LA}$ & - & - & $\uparrow$ \\
\hline \multirow[t]{3}{*}{$67(67)$} & \multirow[t]{3}{*}{$21 / 28$} & \multirow[t]{3}{*}{$\mathrm{LI} / \mathrm{LA}$} & - & - & $\uparrow$ \\
\hline & & & - & - & $\uparrow$ \\
\hline & & & - & - & $\uparrow$ \\
\hline \multirow[t]{2}{*}{$68(68 / 60)$} & \multirow[t]{2}{*}{$19 / 28$} & \multirow[t]{2}{*}{ NINDS } & $\uparrow$ & $=$ & - \\
\hline & & & $\uparrow$ & $\uparrow$ & - \\
\hline \multirow[t]{2}{*}{$73(72)$} & \multirow[t]{2}{*}{$14 / 28$} & \multirow[t]{2}{*}{ image-based } & - & - & $\uparrow$ \\
\hline & & & - & - & $\uparrow$ \\
\hline \multirow[t]{2}{*}{$68(66)$} & \multirow[t]{2}{*}{$21 / 28$} & \multirow[t]{2}{*}{ OCsP [50] } & $\downarrow$ & $=$ & $\uparrow$ \\
\hline & & & $=$ & $\uparrow$ & $\uparrow$ \\
\hline $68(66)$ & $19 / 28$ & NINDS & $=$ & $=$ & - \\
\hline $72(72 / 67)$ & $16 / 28$ & OCSP & $=$ & - & $=$ \\
\hline $66(66 / 67)$ & $16 / 28$ & clinic- and image-based & $=$ & - & $=$ \\
\hline $74(74 / 75)$ & $15 / 28$ & OCSP & $\uparrow$ & - & - \\
\hline $74(74 / 73)$ & $14 / 26$ & OCSP & \multicolumn{3}{|c|}{ association TT genotype with lacunar stroke } \\
\hline $67(67)$ & $21 / 28$ & LI/LA & - & - & $\uparrow$ \\
\hline \multirow[t]{2}{*}{$68(68 / 60)$} & \multirow[t]{2}{*}{$19 / 28$} & \multirow[t]{2}{*}{ NINDS } & $\uparrow$ & $\uparrow$ & - \\
\hline & & & $\uparrow$ & $=$ & - \\
\hline $74(74 / 75)$ & $15 / 28$ & OCSP & $=$ & - & - \\
\hline $66(66 / 67)$ & $16 / 28$ & clinic- and image-based & $\uparrow$ & - & $\downarrow$ \\
\hline & & & $\uparrow$ & - & $\downarrow$ \\
\hline $66(67)$ & $20 / 28$ & LI/LA & - & - & $\uparrow$ \\
\hline & & & MTHFR & llele more frequer & it in LA \\
\hline $65(67)$ & $16 / 28$ & $\mathrm{LI} / \mathrm{LA}$ & - & - & $\uparrow$ \\
\hline $66(66 / 67)$ & $16 / 28$ & clinic- and image-based & $\uparrow$ & - & - \\
\hline
\end{tabular}


iosis compared with controls [13]. These results suggest an acute-phase response of the endothelium but no chronic endothelial activation. The prolonged elevated levels of ICAM-1 are probably due to white blood cell activation in the chronic phase.

\section{Homocysteine, a Toxin for the Endothelium}

Genetic factors, environmental factors or a combination of both can cause elevated levels of homocysteine, which can lead to endothelial dysfunction [48].

Three studies have reported on homocysteine in lacunar stroke patients. All studies found significantly higher levels of homocysteine in patients, especially in those with leukoaraiosis $[11,18,30]$.

We found 2 studies concerning the most frequent genetic defect involving the enzyme methylenetetrahydrofolate reductase. Eikelboom et al. [30] found an equal distribution of the methylenetetrahydrofolate reductase genotype between stroke subtypes, but further subtyping of lacunar stroke patients showed an association with the ischemic leukoaraiosis subtype [11].

\section{Conclusions and Future Options}

In this systematic review, we reviewed papers on endothelial function in patients with lacunar stroke. A proper definition of endothelial dysfunction is missing, but it is generally accepted that endothelial activation and eventually dysfunction - represents the conversion of a quiescent phenotype towards a host defense response due to prolonged and/or repeated exposure to cardiovascular risk factors $[4,5,40]$. In our search strategy, we used different search terms to bypass this definition problem.

Although the assessment of endothelial function was quite diverse, elevated levels of serum markers suggestive of endothelial activation (e.g. sTM, vWF, TFPI), abnormal values of FMD as an indicator of endothelial function and elevated levels of homocysteine and ADMA were all associated with lacunar stroke in the chronic phase, especially in lacunar stroke with concomitant white matter lesions and silent lacunar infarcts.

However, uniform and robust conclusions are difficult to draw due to the heterogeneity of the studies. First, patient populations $[9,12,14,15,20,23,31,32,34,35]$ were described using different classification systems for ischemic stroke, such as the Trial of Org 10172 in Acute Stroke Treatment criteria [49], the Oxfordshire Community Stroke Project classification [50] and the National Institute of Neurological Disorders and Stroke Ad Hoc Com- mittee classification [51]. The use of different definitions probably leads to different case series of lacunar stroke patients studied, making the results difficult to compare. Second, while most studies regarded lacunar stroke as a homogeneous disease, pathological [52] and clinical [53, 54] studies support the hypothesis that two forms of lacunar strokes exist, i.e. isolated lacunar infarct and lacunar stroke with concomitant silent lacunar infarcts and diffuse white matter lesions. Only some studies classified lacunar stroke according to these subtypes $[10,11,13,18$, 19], and it were these studies that found the clearest associations between endothelial dysfunction and lacunar stroke. This suggests that endothelial dysfunction might be especially involved in cerebral small-vessel disease due to lipohyalinosis. Consequently, we propose that future studies should precisely classify the type of lacunar stroke using the established clinical criteria of lacunar syndromes [55] combined with MRI findings [56], without inclusion of a risk factor profile in the classification system [57].

Another limitation was that several studies [9, 23, 35, 39] measured markers of endothelial dysfunction only in the acute phase of the lacunar stroke. The results of these studies reflect an acute-phase response of endothelium instead of a long-term process of endothelial dysfunction. Furthermore, the studies published so far cannot establish whether the endothelial dysfunction is causative or consecutive. Obviously, it would be ideal to collect samples before the event occurs in a population-based design; however, this would require a very large population. The second best choice would be to collect samples several months after the event and to repeat the sample collection, thereby excluding the influence of the acute-phase response, and follow patients clinically as well as by brain MRI for progression of silent cerebral small-vessel disease.

None of the markers described are brain-specific endothelial markers [58]. Also, the mere presence of cardiovascular risk factors (e.g. diabetes) [4], symptomatic disease of large vessels of the brain [14, 31,34] and heart [42] leads to elevated levels of endothelial markers. However, studies on subtypes of lacunar stroke $[11,13,18,19]$ found differences related to concomitant white matter lesions and asymptomatic lacunar infarcts, after adjustment for conventional vascular risk factors. On the other hand, controls with symptomatic large-vessel disease were not included in these studies. Ideally, future studies should include controls with symptomatic atherosclerotic disease (e.g. coronary and carotid disease) and asymptomatic controls with a similar risk factor profile. In all pa- 
tients, the burden of generalized atherosclerotic disease should be measured by objective methods as intima-media thickness.

A final shortcoming of the reviewed studies was that they focused on serum markers of endothelial dysfunction (TM), on causative agents (homocysteine) or on function assessment (FMD). For the future, it would be best to combine these different methods in the same patients.

Finally, it is postulated that endothelial dysfunction is the first step in dysfunction of the BBB [8]. We found only 1 paper concerning BBB dysfunction in lacunar stroke, in which preliminary imaging data, suggesting leakage of the $\mathrm{BBB}$, are presented [22]. So more studies on function and integrity of the BBB are necessary.
In conclusion, the current literature suggests that endothelial dysfunction might be involved in the pathogenesis of lacunar stroke, especially in those patients with multiple lacunar infarcts and ischemic white matter lesions. For the future, patients should be classified by the combination of clinical symptoms and the results of brain MRI. Besides clinical follow-up, disease progression should be evaluated by repeated MRI. The endothelial function should be tested in the chronic phase after the lacunar stroke (3 months) and repeated at fixed intervals, applying the whole spectrum of endothelial function tests. This would allow biochemical markers of endothelial function to be related to the endothelial function itself and the clinical and radiologic follow-up.

\section{References}

1 Bamford J, Sandercock P, Jones L, Warlow C: The natural history of lacunar infarction: the Oxfordshire Community Stroke Project. Stroke 1987; 18:545-551.

2 Fisher CM: Lacunes: small, deep cerebral infarcts. Neurology 1965;15:774-784.

-3 Fisher CM: The arterial lesions underlying lacunes. Acta Neuropathol (Berl) 1968;12: $1-15$.

4 Deanfield JE, Halcox JP, Rabelink TJ: Endothelial function and dysfunction: testing and clinical relevance. Circulation 2007;115: 1285-1295.

5 Blann AD: Endothelial cell activation, injury, damage and dysfunction: separate entities or mutual terms? Blood Coagul Fibrinolysis 2000;11:623-630.

6 Lammie A: The role of oedema in lacune formation. Cerebrovasc Dis 1998;8:246.

7 Wardlaw JM: What causes lacunar stroke? J Neurol Neurosurg Psychiatry 2005;76:617619.

-8 Wardlaw JM, Sandercock PA, Dennis MS, Starr J: Is breakdown of the blood-brain barrier responsible for lacunar stroke, leukoaraiosis, and dementia? Stroke 2003;34:806812.

$\checkmark 9$ Chen PL, Wang PY, Sheu WH, Chen YT, Ho YP, Hu HH, Hsu HY: Changes of brachial flow-mediated vasodilation in different ischemic stroke subtypes. Neurology 2006; 67:1056-1058.

10 Gormley K, Bevan S, Hassan A, Markus HS: Polymorphisms in genes of the endothelin system and cerebral small-vessel disease. Stroke 2005;36:1656-1660.
Hassan A, Hunt BJ, O'Sullivan M, Bell R, D'Souza R, Jeffery S, Bamford JM, Markus HS: Homocysteine is a risk factor for cerebral small vessel disease, acting via endothelial dysfunction. Brain 2004;127:212-219.

12 Jannes J, Hamilton-Bruce MA, Pilotto L, Smith BJ, Mullighan CG, Bardy PG, Koblar SA: Tissue plasminogen activator $-7351 \mathrm{c} / \mathrm{t}$ enhancer polymorphism is a risk factor for lacunar stroke. Stroke 2004;35:1090-1094.

13 Hassan A, Hunt BJ, O'Sullivan M, Parmar K, Bamford JM, Briley D, Brown MM, Thomas DJ, Markus HS: Markers of endothelial dysfunction in lacunar infarction and ischaemic leukoaraiosis. Brain 2003;126:424-432.

14 Kozuka K, Kohriyama T, Nomura E, Ikeda J, Kajikawa H, Nakamura S: Endothelial markers and adhesion molecules in acute ischemic stroke - sequential change and differences in stroke subtype. Atherosclerosis 2002;161:161-168.

15 Yahashi Y, Kario K, Shimada K, Matsuo M: The 27-bp repeat polymorphism in intron 4 of the endothelial cell nitric oxide synthase gene and ischemic stroke in a japanese population. Blood Coagul Fibrinolysis 1998;9: 405-409.

16 Kario K, Matsuo T, Kobayashi H, Asada R, Matsuo M: 'Silent' cerebral infarction is associated with hypercoagulability, endothelial cell damage, and high Lp(a) levels in elderly Japanese. Arterioscler Thromb Vasc Biol 1996;16:734-741.

17 Pretnar-Oblak J, Sabovic M, Sebestjen M, Pogacnik T, Zaletel M: Influence of atorvastatin treatment on L-arginine cerebrovascular reactivity and flow-mediated dilatation in patients with lacunar infarctions. Stroke 2006;37:2540-2545.
Khan U, Hassan A, Vallance P, Markus HS: Asymmetric dimethylarginine in cerebral small vessel disease. Stroke 2007;38:411413.

19 Hassan A, Gormley K, O’Sullivan M, Knight J, Sham P, Vallance P, Bamford J, Markus H: Endothelial nitric oxide gene haplotypes and risk of cerebral small-vessel disease. Stroke 2004;35:654-659.

20 Nomura E, Kohriyama T, Kozuka K, Kajikawa $\mathrm{H}$, Nakamura S, Matsumoto M: Significance of serum soluble thrombomodulin level in acute cerebral infarction. Eur J Neurol 2004;11:329-334.

21 Kubo M, Hata J, Ninomiya T, Matsuda K, Yonemoto K, Nakano T, Matsushita T, Yamazaki K, Ohnishi Y, Saito S, Kitazono T, Ibayashi S, Sueishi K, Iida M, Nakamura Y, Kiyohara Y: A nonsynonymous SNP in PRKCH (protein kinase $\mathrm{C}$ eta) increases the risk of cerebral infarction. Nat Genet 2007;39:212-217.

22 Wardlaw JM, Farrall A, Armitage PA, Carpenter T, Chappell F, Doubal F, Chowdhury D, Cvoro V, Dennis MS: Changes in background blood-brain barrier integrity between lacunar and cortical ischemic stroke subtypes. Stroke 2008;39:1327-1332.

23 de Leeuw FE, van Huffelen A, Kappelle J: Cerebrovascular reactivity in patients with a recent lacunar infarction. J Neurol 2003;250: 232-233.

24 Hund-Georgiadis M, Zysset S, Naganawa S, Norris DG, Von Cramon DY: Determination of cerebrovascular reactivity by means of FMRI signal changes in cerebral microangiopathy: a correlation with morphological abnormalities. Cerebrovasc Dis 2003; 16:158165. 
-25 Molina C, Sabin JA, Montaner J, Rovira A, Abilleira S, Codina A: Impaired cerebrovascular reactivity as a risk marker for first-ever lacunar infarction: a case-control study. Stroke 1999;30:2296-2301.

26 Cupini LM, Diomedi M, Placidi F, Silvestrini M, Giacomini P: Cerebrovascular reactivity and subcortical infarctions. Arch Neurol 2001;58:577-581.

-27 Pretnar-Oblak J, Zaletel M, Zvan B, Sabovic M, Pogacnik T: Cerebrovascular reactivity to $\mathrm{L}$-arginine in patients with lacunar infarctions. Cerebrovasc Dis 2006;21:180-186.

-28 Cherian P, Hankey GJ, Eikelboom JW, Thom J, Baker RI, McQuillan A, Staton J, Yi Q: Endothelial and platelet activation in acute ischemic stroke and its etiological subtypes. Stroke 2003;34:2132-2137.

-29 Elbaz A, Poirier O, Moulin T, Chedru F, Cambien F, Amarenco P: Association between the Glu298Asp polymorphism in the endothelial constitutive nitric oxide synthase gene and brain infarction. The GENIC investigators. Stroke 2000;31:1634-1639.

30 Eikelboom JW, Hankey GJ, Anand SS, Lofthouse E, Staples N, Baker RI: Association between high homocyst(e)ine and ischemic stroke due to large- and small-artery disease but not other etiologic subtypes of ischemic stroke. Stroke 2000;31:1069-1075.

-31 Nomura E, Kohriyama T, Kozuka K, Kajikawa H, Nakamura S: Sequential changes in von Willebrand factor and soluble thrombomodulin in acute ischemic stroke. J Stroke Cerebrovasc Dis 2001;10:257-264.

$\checkmark 32$ Hou L, Osei-Hyiaman D, Yu H, Ren Z, Zhang Z, Wang B, Harada S: Association of a 27-bp repeat polymorphism in ecNOS gene with ischemic stroke in Chinese patients. Neurology 2001;56:490-496.

>33 Markus HS, Ruigrok Y, Ali N, Powell JF: Endothelial nitric oxide synthase exon 7 polymorphism, ischemic cerebrovascular disease, and carotid atheroma. Stroke 1998;29: 1908-1911.

>34 Catto AJ, Carter AM, Barrett JH, Bamford J, Rice PJ, Grant PJ: Von Willebrand factor and factor VIII: $C$ in acute cerebrovascular disease. Relationship to stroke subtype and mortality. Thromb Haemost 1997;77:11041108.
35 Bath PM, Blann A, Smith N, Butterworth RJ Von Willebrand factor, p-selectin and fibrinogen levels in patients with acute ischaemic and haemorrhagic stroke, and their relationship with stroke sub-type and functional outcome. Platelets 1998;9:155-159.

36 Maeda H, Matsumoto M, Handa N, Hougaku $\mathrm{H}$, Ogawa S, Itoh T, Tsukamoto Y, Kamada T: Reactivity of cerebral blood flow to carbon dioxide in various types of ischemic cerebrovascular disease: evaluation by the transcranial Doppler method. Stroke 1993; 24:670-675.

37 Lavi S, Egbarya R, Lavi R, Jacob G: Role of nitric oxide in the regulation of cerebral blood flow in humans: chemoregulation versus mechanoregulation. Circulation 2003; 107:1901-1905.

38 Lavi S, Gaitini D, Milloul V, Jacob G: Impaired cerebral $\mathrm{CO}_{2}$ vasoreactivity: association with endothelial dysfunction. Am J Physiol Heart Circ Physiol 2006;291:H1856H1861.

39 Mochizuki Y, Oishi M, Takasu T: Cerebral blood flow in single and multiple lacunar infarctions. Stroke 1997;28:1458-1460.

40 Lentz SR, Rodionov RN, Dayal S: Hyperhomocysteinemia, endothelial dysfunction, and cardiovascular risk: the potential role of ADMA. Atheroscler Suppl 2003;4:61-65.

41 Spronk HM, Govers-Riemslag JW, ten Cate $\mathrm{H}$ : The blood coagulation system as molecular machine. Bioessays 2003;25:12201228.

$\checkmark 42$ Vischer UM: Von Willebrand factor, endothelial dysfunction, and cardiovascular disease. J Thromb Haemost 2006;4:1186-1193.

43 Crawley JT, Lane DA: The haemostatic role of tissue factor pathway inhibitor. Arterioscler Thromb Vasc Biol 2008;28:233-242.

44 Ladenvall P, Wall U, Jern S, Jern C: Identification of eight novel single-nucleotide polymorphisms at human tissue-type plasminogen activator (t-PA) locus: association with vascular t-PA release in vivo. Thromb Haemost 2000;84:150-155.

45 Springer TA: Adhesion receptors of the immune system. Nature 1990;346:425-434.

46 Carlos TM, Harlan JM: Leukocyte-endothelial adhesion molecules. Blood 1994;84: 2068-2101.

-47 Gearing AJ, Newman W: Circulating adhesion molecules in disease. Immunol Today 1993;14:506-512.
48 Woo KS, Chook P, Lolin YI, Cheung AS, Chan LT, Sun YY, Sanderson JE, Metreweli C, Celermajer DS: Hyperhomocyst(e)inemia is a risk factor for arterial endothelial dysfunction in humans. Circulation 1997;96: 2542-2544.

49 Adams HP Jr, Bendixen BH, Kappelle LJ, Biller J, Love BB, Gordon DL, Marsh EE 3rd: Classification of subtype of acute ischemic stroke. Definitions for use in a multicenter clinical trial. TOAST. Trial of Org 10172 in Acute Stroke Treatment. Stroke 1993;24:3541.

50 Bamford J, Sandercock P, Dennis M, Burn J, Warlow C: Classification and natural history of clinically identifiable subtypes of cerebral infarction. Lancet 1991;337:1521-1526.

51 Special report from the National Institute of Neurological Disorders and Stroke. Classification of cerebrovascular diseases III. Stroke 1990;21:637-676.

52 Fisher CM: Capsular infarcts: the underlying vascular lesions. Arch Neurol 1979;36:6573.

53 de Jong G, Kessels F, Lodder J: Two types of lacunar infarcts: further arguments from a study on prognosis. Stroke 2002;33:20722076

54 Boiten J, Lodder J, Kessels F: Two clinically distinct lacunar infarct entities? A hypothesis. Stroke 1993;24:652-656.

55 Donnan GA, Norrving B, Bammer R, Bogousslavsky J: Classification of subcortical infarcts; in Donnan GA, Norrving B, Bamford J, Bogousslavsky J (eds): Subcortical Stroke. New York, Oxford University Press Inc, 2002, pp 27-34.

56 Fazekas F, Kleinert R, Offenbacher H, Schmidt R, Kleinert G, Payer F, Radner H, Lechner H: Pathologic correlates of incidental MRI white matter signal hyperintensities. Neurology 1993;43:1683-1689.

57 Jackson C, Sudlow C: Are lacunar strokes really different? A systematic review of differences in risk factor profiles between lacunar and nonlacunar infarcts. Stroke 2005;36: 891-901.

58 Crawley J, Lupu F, Westmuckett AD, Severs NJ, Kakkar VV, Lupu C: Expression, localization, and activity of tissue factor pathway inhibitor in normal and atherosclerotic human vessels. Arterioscler Thromb Vasc Biol 2000;20:1362-1373. 